ARTICLE

\title{
Physician self-care
}

J Kirby, ${ }^{1}$ MB ChB, DCH (SA), DipObst (SA), MFamMed, Dip Homeopathy (SA), MFHom (UK); P Lück, ${ }^{2} \mathrm{MB}$ ChB, MPhil Palliative Medicine

${ }^{1}$ Integrative Practice (Family Medicine and Homeopathy); St Bernard's Hospice, East London; and Mindfulness-Based Stress Reduction Programme, East London, South Africa

${ }^{2}$ Gauteng Centre of Excellence for Palliative Care, Chris Hani Baragwanath Academic Hospital, Wits Centre for Palliative Care, Johannesburg, South Africa

Corresponding author: J Kirby (janine@hazymoon.co.za)

Many of us have worked in the interminable queues of outpatient departments. After a long day, we are greeted with the hopeful, tired faces of families with their ill loved ones. We are meant to be able to heal and cure. Yet, we often run out of options, treatments seem ineffective, and we have to hold the hands of those who are dying.

Doctors have mostly been trained to cure. They make significant sacrifices in family life, sleep, personal time and hobbies to be able to pursue this ideal. Moving away from cure to compassionate care of dying patients, is a paradigm shift. This can be particularly difficult when caring for children with terminal illness. It is easier to accept death in the elderly as it is part of the natural order of life. Caring for dying children can, however, be draining on both staff and families.

S Afr Med J 2014;104(7):513. DOI:10.7196/SAMJ.8472

Helping, fixing and serving represent three different ways of seeing life. When you help you see life as weak. When you fix you see life as broken. When you serve, you see life as whole. (Dr Rachel Naomi Remen)

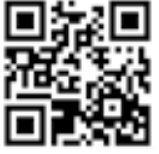

Burnout and compassion fatigue among doctors and medical students is a well-recognised entity, with an estimated prevalence of up to $60 \% .^{[1]}$ Burnout refers to the stresses between doctors and their work environment, while compassion fatigue relates to stresses in the doctor-patient relationship. Both have a negative impact on patient care, increasing the number of medical errors, lowering both patient and physician satisfaction and lengthening the recovery phase..$^{[1-3]}$

\section{Symptoms and signs of burnout ${ }^{[1]}$}

- Overwhelming physical and emotional exhaustion

- Feelings of cynicism and detachment from one's work

- A sense of ineffectiveness and lack of accomplishment

- Over-identification and over-involvement

- Irritability and hyper-vigilance

- Social withdrawal

- Professional and personal boundary violations

- Poor judgement

- Perfectionism and rigidity

- Questioning the meaning of life

- Questioning prior religious beliefs

- Interpersonal conflicts

- Avoidance of emotionally difficult situations

- Addictive behaviours

- Numbness and detachment

- Difficulty in concentrating

- Frequent illnesses - headaches, gastrointestinal disturbances, immune impairment

- Low morale

- Impaired work performance

- Staff conflict
Joan Halifax ${ }^{[4]}$ has taught at programmes in palliative care for health professional caregivers for many years. She identified frequent challenges facing healthcare workers. These include the following:

Pathological altruism, when practitioners are unable to clearly define boundaries between themselves and the patient. Doctors often struggle to balance the demands of their own personal and family time with work.

Vital exhaustion from ongoing work demands.

Vicarious trauma from prolonged and repeated exposure to the suffering of others. In end-of-life care, especially for children, one can easily become emotionally involved with the patients and their family, suffering together with the family when the patient dies.

Moral distress. Anger and outrage caused by a perceived injustice or violation of an ethical standard such as respect or confidentiality.

Systemic violence or problems in an institution.

Palliative care practitioners have identified the following additional stressors in their subspecialty: the constant exposure to death, inadequate time with dying patients, growing workload and increasing number of deaths, inadequate coping with one's emotional response to dying patients, need to carry on 'as usual' in the wake of patients' deaths, communication difficulties with dying patients and relatives, and identification of or developing friendships with patients. ${ }^{[4]}$ For junior doctors this may be even more difficult, because they have limited exposure to death in families outside the hospital. On the other hand, the family practitioner has often come a long way with the patient and family, which can add to feelings of responsibility, inadequacy and grief.

In order to be a well-rounded healthcare professional not at risk of burnout or compassion fatigue, the healthcare practitioner should recognise him/herself as a resource that needs nurturing and care, rather than a limitless skilled tool at the mercy of their environment. Self-care is essential and necessary. 


\section{Practise what you preach}

Simple lifestyle changes can make an enormous difference to one's quality of life. Enough sleep, moderate exercise and a healthy diet are key cornerstones. Physicians should consider prioritising their own health and set time limits to be able to engage in the foregoing activities.

Furthermore, strong supportive social networks are also valuable and it is helpful for family and friends to understand the stresses of healthcare workers. Groups of doctors, so-called Balint groups, can meet regularly to discuss ethical and medical problems. ${ }^{[5]}$ Doctors should be encouraged to seek help and counselling when they are stressed, rather than self-medicate and try to present a strong front.

\section{Mindfullness}

When doctors are less self-aware, they tend to lose perspective and become stressed. Those who are more self-aware, tend to experience greater job satisfaction and empathic and mutually healing relationships with their patients. They are more likely to be patient centred, and their patients are more satisfied. ${ }^{[5]}$ Krasner et al. ${ }^{[6]}$ in an important study, found that physicians who participated in a programme that included mindfulness meditation, self-awareness exercises, appreciative interviews, teaching and discussion had shortand long-term improvement in their well-being and were more patient centred.

Tania Singer ${ }^{[7,8]}$ at the Max Planck Institute in Germany has been at the forefront of research in empathy and compassion. Empathy is crucial for social interaction, but taking on the suffering of others, especially among healthcare workers, can be draining. In a landmark paper in 2004, Singer ${ }^{[7]}$ identified the following three emotional states:

\section{Emotional contagion}

This is the tendency to mimic and mirror the emotions of another person. Yawn contagion is an example of emotional contagion, i.e. when one person in a group yawns, the rest of the group unconsciously follow. It is an automated response and does not come with an awareness of the emotions of the other.

\section{Empathy}

This is the capacity to sense the inner emotional state of another person, simulating their actions, emotions and thoughts. There is no obvious pro-social behaviour or action linked to empathy. However, unlike emotional contagion, the person is aware that his/ her emotional state has been provoked by another.

In functional magnetic resonance imaging studies, the empathiser and participant were studied simultaneously. ${ }^{[0,10]}$ The participant was given a painful stimulus while the empathiser was aware of the pain being inflicted. Activation of the same brain areas occurred in the empathiser and in the participant who was experiencing the pain. The rostral anterior cingulate cortex, bilateral anterior insula, brainstem and cerebellum are referred to as the 'pain matrix', because these areas are involved in pain processing, judging the severity and level of discomfort of the stimulus. The somatosensory regions of the brain have also been shown to be activated, thus producing the 'feeling sense' of the pain experience of another person.

The more one is aware of one's own bodily states, the more the insula and anterior cingulate cortex are activated and the better one relates to the emotions of others.

\section{Compassion}

This has been defined as the emotion one experiences when feeling concern for another persons's suffering and is linked to the deep desire and motivation to alleviate this suffering. Compassion is linked to activation of the motor cortex.

The past decade has seen an unprecedented explosion in our understanding of the structure and function of the brain, the activity of which is malleable and plastic. ${ }^{[1]]}$ In recent years, we have begun to understand more about how both the neural pathways and anatomy of the brain can be altered by purposefully cultivating different modes of being.

Practitioners who are more in touch with themselves and selfaware are more compassionate and able to cope with the stresses and burdens of patient care. Doctors can practise putting themselves into the shoes of others, while simultaneously caring for their own wellbeing and becoming kinder towards themselves, their patients and their families. ${ }^{[12]}$

The cultivation of greater awareness and compassion can be enhanced through mindfulness training. Mindfulness has been defined as purposefully and non-judgementally paying attention in a particular way in the present moment. ${ }^{[13]}$ It is an ability that can be exercised and cultivated through practice, e.g. awareness of breathing, seating posture, eating, daily routine activities and walking meditation. When practised regularly, these exercises allow one to cultivate patience, awareness, attention, discernment, greater non-judgemental openness, self-kindness and compassion towards oneself and one's patients. Doctors who engage in regular self-care and mindful practice tend to be invigorated rather than depleted by their daily interactions with their patients.

\section{Short breathing meditation}

Sit. Notice. Breathe.

For a few brief moments, right now, put down pencil and paper, and once you have read this paragraph, stop looking at the screen. Sit back in your chair, or wherever you find yourself, and allow your body to be supported upright as best you can. Notice the sensations of movement of your own breathing. Do you notice the movement of air at the nostrils; movement of the ribcage as breath enters and leaves the lungs; movement at the belly as it rises with breathing in, falls with breathing out, as the diaphragm expands and contracts? There is no need to change or judge the rhythm of your breathing. Just engage a sense of curiosity about each breath, this breath, and the rhythm that it already has at this very moment.

\section{Short eating meditation ${ }^{[14]}$}

Drink tea, eat mindfully.

While eating and drinking pay attention to this activity, noticing the taste of the drink and food in your mouth, the aroma, the colours, the flavours, and the different sensations of textures on your tongue. Notice the movement involved in bringing the food and drink to your mouth, the movement of the face and the lips, the swallowing motions, and any other sensations of which you may be aware. Engage a gentle and kind curiosity of what it is you are doing, not needing to change any of it. 


\section{Awareness of routine activities}

Choose one daily routine activity and perform it intentionally, noticing the movement, sensations, thoughts and emotions. Be intimately engaged in what you are attending to and curious about a habitual activity that you give little thought to, e.g. showering, brushing teeth, washing dishes, or anything else you may choose. Observe movement, flow of water, touching of air, or anything else you do that you normally don't notice so intently.

\section{Walking meditation}

Spend a few moments attending just to in- or outdoor walking, choosing a short particular lane (of your own making). Allow your arms to be relaxed, either by your side or held gently in front of or behind your body, and your eyes to focus gently a short distance in front of your body. Notice the sensation in your body of walking legs, feet, the contact and connection made with the walking surface, either barefoot, with stockings, or with shoes. Observe the action of walking - lifting - shifting - placing - lifting - shifting - placing ... Notice breathing, thoughts, other sensations, and emotions, if helpful naming them in your head, and letting go of needing to make a story of any of them, returning your attention gently each time to simply noticing walking.

\section{References}

1. Kearney MK, Weininger RB, Vachon MLS, Harrison RL, Mount BM. Self-care of physicians caring for patients at the end of life. JAMA 2009;301(11):1155-1164. [http://dx.doi.org/10.1001/ jama.2009.352]

2. Shanafeldt T, Adjei A, Meyskens FL. When your favourite patient relapses: Physician grief and wellbeing in the practice of oncology. J Clin Oncol 2003;21(13):2616-2619. [http://dx.doi.org/10.1200/ JCO.2003.06.075]

3. Shanafelt T, Dyrbye L. Oncologist burnout: Causes, consequences, and responses. J Clin Oncol 3. Shanafelt T, Dyrbye L. Oncologist burnout: Causes, consequences,
2012;30(11):1235-1241. [http://dx.doi.org/10.1200/JCO.2011.39.7380]

4. Halifax J. The precious necessity of compassion. Journal of Pain and Symptom Management 2011;41(1):146-153. [http://dx.doi.org/10.1016/j.jpainsymman.2010.08.010]

5. Novack DH, Suchman AL, Clark W, Epstein RM, Najberg E, Kaplan C. Calibrating the physician. Personal awareness and effective patient care. JAMA 1997;278(6):502-509.

6. Krasner MS, Epstein RM, Beckman H, et al. Association of an educational program in mindfu communication with burnout, empathy, and attitudes among primary care physicians. JAMA 2009;302(12):1284-1293. [http://dx.doi.org/10.1001/jama.2009.1384]

7. Singer T, Seymour B, O'Doherty J, Kaube H, Dolan RJ, Frith C. Empathy for pain involves the affective but not sensory components of pain. Science 2004;303(5661):1157-1162. [http://dx.doi. org/10.1126/science.1093535]

8. Cognitive Neuroscience Society. Feeling Others' Pain: Transforming Empathy into Compassion. 2013. http://www.cogneurosociety.org/empathy_pain/ (accessed 14 February 2014).

De Vignemont F, Singer T. The empathic brain: How, when and why? Trends in Cognitive Science . De Vignemont F, Singer T. The empathic brain: How, when and why?
2006;10(10):435-441. [http://dx.doi.org/10.1016/j.tics.2006.08.008]

2006;10(10):435-441. [http://dx.doi.org/10.1016/j.tics.2006.08.008]
10. Hein G, Singer T. I know how you feel but not always: The empathic brain and its modulation. Current . Hein G, Singer T. I know how you feel but not always: The empathic brain and its modulation. Cu
Opinion in Neurobiology 2008;18(2):153-158. [http://dx.doi.org/10.1016/j.conb.2008.07.012]

1. Davidson RJ, Lutz A. Buddha's brain: Neuroplasticity and meditation. IEEE Signal Process Magazine 2008:25(1):174-176. [http://dx.doi.org/10.1109/MSP.2008.4431873]

12. Weng HY, Fox AS, Stodala DE, et al. Compassion training alters altruism and neural responses to suffering. Psychol Sci 2013;24(7):1171-1180. [http://dx.doi.org/10.1177/0956797612469537]

13. Black DS. A brief definition of mindfulness: Mindfulness Research Guide. 2011. http://www. mindfulexperience.org/resources/brief_definition.pdf (accessed 23 March 2014).

14. Lück P. Mindfulness - Our Sixth Sense - Series Introduction. http://www.ehospice.com/ArticleView/ tabid/10686/ArticleId/8575/language/en-GB/Viewaspx\#.UzCxdF7R32A (accessed 23 March 2014). 